\title{
Gender Differences in the Perception of a Student Information System
}

\author{
Rana Alhajri ${ }^{1}$, Ahmed Al-Hunaiyyan ${ }^{2}$, Bareeq Alghannam ${ }^{3}$, Abdullah Alshaher ${ }^{4}$ \\ Computer Science Department ${ }^{1}$ \\ Computer Science and Information Systems Department ${ }^{2,3,4}$ \\ Public Authority for Applied Education and Training, Kuwait
}

\begin{abstract}
There is growing recognition that electronic student information systems support college administrations and enhance student performance. These systems must fulfill their user's needs by understanding gender differences among users. This study analyzes gender variations concerning the utilization of online student information systems (SIS), with its central concern being how the dynamics of user experience (UX) are affected. A broad agreement is evident throughout the literature that gender is a crucial aspect when assessing human-computer interactions. Consequently, usability factors are brought into question, although there is some indication among researchers that too much weight is being applied. Study findings are gathered to represent the hedonic and pragmatic qualities of users, with clarifications of students' perspectives deducted from qualitative methods, together with a UX examination made via Kuwait's Public Authority for Applied Education and Training (PAAET) institute. Results suggest that none of the differing approaches and habits the two genders have toward UX should be considered as substantial, with the overall sample recording a perception of UX that is "slightly positive". Furthermore, this research highlights difficulties with usability that developers may wish to take onboard for system upgrades.
\end{abstract}

Keywords-Gender differences; student information system; human-computer interaction; usability; user experience; perceptions

\section{INTRODUCTION}

Systems incorporated into educational facilities need to enhance learning methods by offering those involved an original and dynamic experience filled with a wide range of learning avenues and interests, embracing extra-curricular potential and innovative resources where possible. This needs to be achieved while making the most of e-labs, e-libraries, etutoring potentials, simulations, etc. Other beneficial avenues may incorporate Archiving System, as well as include Student Information System (SIS), and e-Advising systems [1], together with learning management systems (LMS) [2]. With SIS, students can access range of functionalities that allow for handling administrative issues - vital for both educators and learners [3,4]. Studies have confirmed that SIS components make a notable difference in all parties' activities and actions $[5,6]$.

The key SIS features should be determined, meaning that a fitting evaluation process should be ascertained to make the most of potential. Education facilities should not overlook the importance of integrating with SIS, which has become crucial for robust learning journeys. Its utilization is vital for carrying out a range of college organizational actions, as well as the upgrading of student capabilities. Plus, firm assessment of SIS usability is critical for a wide range of participants, but learners especially, while research carried out within HCI closely relates to the system's ultimate functionality. Assessing how and to what degree a certain system, resource, or service offers usability to those it has been designed for is necessary for both purpose and setting [7]. As a result, developers are required to continue enhancing their systems according to the feedback and assessment of their users, including in cultural and social contexts [8], as well as a personal preference [9], age and gender [10].

A range of varied methods offers guidance in these respects. Still, widely recognized aspects are set out in the literature, for example, with [11], who identifies hedonic and pragmatic qualities as two leading interactive concepts. In this sense, 'pragmatic' concerns task-related aspects and the effectiveness of methods to support particular actions, leading to goal fulfillment. Whereas 'hedonic' concerns those aspects not related to tasks, they are nevertheless crucial for the resource enabling users to pursue their objective. Research covering these dynamics is quite extensive [12, 13, 14], meaning that a range of analyses are available to assist with judging the extent to which systems satisfy their users' goals.

Different characteristics and personalities, for which gender can be important, might affect how learners' approach and utilize online technology. A student's perspective will differ according to their own individual traits, including gender and age, as well as previous experience that dictates the opinions and habits, they develop [15]. Gender, in particular, can prove a defining aspect as far as Kuwait is concerned, as men and women tend to develop different approaches toward technology use. Understanding why this is present in respect of cultural norms can be crucial for aligning systems with a largely conservative society's cultural factors. In general, it can be predicted that both men and women in Kuwait will become accustomed to utilizing online technology to enhance their social fabrics against a backdrop of collectivist culture [16, 17]. However, research into how such mobile-learning behaviors vary between ages and genders has not been extensive enough as far as Kuwait is concerned [18]. This research endeavors to make up for this with an SIS assessment based on genderdriven factors, with a particular focus on UX.

Six sections make up the paper in total. This introduction is followed by a section on research objectives before Section 3 provides a review of the relevant literature. The methodology 
is then covered in Section 4, before a discussion of the results in Section 5, and finally a conclusion.

\section{RESEARCH OBJECTIVES}

This research has been carried out to clarify learners' perspectives of SIS, together with analyzing their user experience (UX) via the Public Authority for Applied Education and Training (PAAET). It offers the first insight into these dynamics, filling a void in the literature and shining a light on Kuwait's education aspects a result [19]. The focus is on assessing SIS within Kuwait, which has not yet been scrutinized, especially concerning gender factors $[18,20]$. Chiefly, we outline two key usability and UX factors: pragmatic and hedonic - i.e., task versus non-task-oriented features [11]. Furthermore, the research explores gender variations concerning opinions of SIS, as well as trialing two vital hypotheses:

H1: Substantial variations exist between the genders when it comes to how students view SIS pragmatically.

$\mathrm{H} 2$ : Substantial variations exist between the genders when it comes to how students view SIS hedonistically.

This research aims to direct system developers regarding beneficial growth avenues that can further enhance SIS utilization. Such enhancement should extend SIS's efficacy and show how users interact with the various resources, consider both genders, and enrich their understanding of its related capabilities [21].

\section{LITERATURE REVIEW}

SIS is vital for enabling stakeholders to grasp key details via extensive reports on how both learners and educators are using systems and the various departments involved, including financial aspects. Robust SIS can prove fulfilling for both the educators and students that rely on these systems, as well as having an overall impact on the progression of academic development [22]. The efficacy of the various software and platforms involved is thoroughly examined in related studies $[23,24,25,26,27,28,29]$, with user satisfaction especially driving the research.

The author in [30] carried out a survey at Allama Iqbal Open University (with responses taken from 173 students in total), which explored key aspect of information quality, system quality, service quality, perceived usefulness, and intent use, and user satisfaction. Most respondents were content with the system's functionalities and technical aspects, though they were more critical of the availability of key information and specific system responses [30]. In contrast, [31] assessed SIS's usability links with late student assignments, declined course registrations, and inaccuracies. In doing so, the resulting advice suggested enhancing the system to allow the institution in question to improve these aspects. In addition, research from [32] targeted analyzing the utilization of student information systems via both educators and learners at Yamen's faculty of oil and minerals.

Several studies have indicated differences between the genders when using technology due to cultural habits and beliefs [33, 34, 8]. The author in [35], in New Zealand, looked at comprehending the differing approaches that male and female learners take to a short message service (SMS). The findings showed notable variations in how both genders recognized applicability, together with the purposes of use, although nothing significant in relation to self-efficacy and convenience. Plus, [36] explored the gender dynamics clear from research on smartphone usage carried out across five nations - the USA, Japan, Korea, Italy, and Sweden. Their findings suggest several usage differences according to gender, together with variations in attitude. The author in [37] explores these factors in the context of Saudi Arabia, for which gender variations are apparent because of cultural tendencies. The author in [38] found that users' perspectives are likely to show extensive variations, including age and gender as defining motivations for such preferences. Indeed, it is crucial to appreciate different views caused by age and gender, as well as culture and background [39]. For example, in a study based on Arab GCC nations, [25] examined the driving factors behind female users being drawn to online bulletins to express themselves. Respondents confirmed that corresponding online enabled them to feel more active and stimulated by subjects they might not otherwise wish to raise in a social context. According to the researchers, all these factors were linked to conservative attitudes of broader society.

There is a similar culture to other Arab nations based on a dominant and collectivist approach regarding Kuwait. As proposed by [17], one specific quality of this tendency is the general approach to social situations, family, and friends, which are all ranked highly among personal priorities [17, 40]. The author in [20] examined learners' perspectives on mobile learning potential via 620 responses from HE institutions throughout Kuwait. The results highlight clear variations due to age and gender while revealing related social and cultural factors. Likewise, [16] explored the impact of culture via Instagram concerning gender differences. The findings show that men are more likely to feel comfortable posting confidential material. In contrast, women feel cautious about whether this meets with the values and pressures of a conservative culture.

Quality of use tends to be understood as 'usability.' Trialing this requires concentration on achievement, including the manner of utilization to suit a pragmatic approach [41] relating to the obtainment of behavioral goals [42]. When starting his research two decades ago, [43] considered the trialing of usability methods to overlook the factors of stimulation, user preferences, and innovation. Consequently, he put forward hedonism to add a new layer of understanding, incorporating aspects unrelated to the carrying out of tasks, such as subjective appeal, aesthetics, and novelty [43]. The author in [44] stressed how vital such features might be for overall system appeal. As a result, [45] considered these features to require more focus than pragmatic ones, so they proposed a user experience (UX) model as a suitable long-term analysis tool [45]. The author in [46] also looked at examining how hedonic and pragmatic features impact users, which they did by adopting the UX model to explore how the many variables interconnect and relate.

An alternative familiar approach to analyzing the two competing dynamics is to define them as the goals of usability 
versus user experience [47]. A few research analyses were carried out, therefore, according to identified pragmatic and hedonic qualities within both usability and user experience [12, $14,46,13]$. As proposed by [38], a subjective approach needs to be adopted when considering user experience matters. Those utilizing the technology may develop a wide range of perspectives or go about meeting their objectives in many varied ways. Plus, additional reasons for various perspectives result from both gender and age [12].

\section{METHODOLOGY}

This section defines the research methodology, setting out the samples, instruments, and procedures that have been employed.

\section{A. Research Sample}

In total, 645 respondents contributed to this research, 525 of whom were female and 120 males. These contributors were sourced from the five PAAET colleges: The College of Basic Education, College of Business Studies, College of Technological Studies, College of Health Sciences, and College of Nursing. Due to the colleges in question educating more female than male students in total, the number of female respondents greatly outweighed male ones. For demographic figures and distribution samples, see Table I.

TABLE I. STUdy SAMPLE (DEMOGRAPHIC DATA)

\begin{tabular}{|l|l|l|l|}
\hline & & No. & \% \\
\hline \multirow{4}{*}{ Gender } & Male & 120 & 18.6 \\
\cline { 2 - 4 } & Female & 525 & 81.4 \\
\hline \multirow{5}{*}{ College } & Business Studies & 307 & 47.6 \\
\cline { 2 - 4 } & Health Sciences & 89 & 13.8 \\
\cline { 2 - 4 } & Basic Education & 135 & 20.9 \\
\cline { 2 - 4 } & Technological Studies & 79 & 12.2 \\
\cline { 2 - 4 } & Nursing & 35 & 5.4 \\
\hline
\end{tabular}

\section{B. Research Instruments}

This study adopts methods that are both quantitative and qualitative in nature to assess the focus group via a survey. Goal Question Metric (GQM) has been applied to produce the questionnaire statements necessary for surveying the focus group. This is a widely recognized top-down method to examining software metrics via objectives [48], with the objectives being set out according to the defined pragmatic and hedonic usability features. Additionally, to align the questionnaire with answering questions related to gender difference, the User Experience Questionnaire (UEQ) is incorporated [49].

The questionnaire material has been adjusted to suit the context of PAAET students. In doing so, punchy sentences were favored to express the rationale, avoiding only words that might lead to respondents feeling ambiguous toward the intended meaning. The focus research carried out recognized that PAAET students are likely to question material in such a manner. In total, 50 students participated in the preparatory focus group, allowing researchers to ask their own methods and wordings so they could enhance for a larger rollout. This process resulted in the 16 questions edited for the final questionnaire.

There were three sections to the final version, as follows. Section 1 focused on obtaining the demographic data of students, as per their gender and academic institution. Section 2 gathered details to reflect pragmatic behaviors, and Section 3 the hedonistic behaviors. To achieve clarity of response, a fivepoint Likert-type scale was utilized as follows: $1=$ Strongly Disagree, $2=$ Disagree, $3=$ Neutral, $4=$ Agree, and $5=$ Strongly Agree. With the questionnaire material edited to best capture the PAAET students' attitudes toward SIS's attitudes, a focus group was then sourced to trial the material's efficacy and upgrade the questions where issues were identified. The questionnaire's applicability was established by defining each theme's interconnections and the representative scores gathered from the 50 participants. SPSS was then also utilized to measure the correlation coefficients. This shows high correlations concerning individual dimensions and the overall score $(\mathrm{p}<0.01)$ calculated as between 0.795 to 0.901 , which shows high internal consistency and construction integrity.

Likewise, the questionnaire's applicability has been analyzed by identifying Cronbach's alpha via SPSS. Consequently, there are high-reliability levels to the questionnaire, with co-efficient degrees of 0.74-0.93 and an overall Cronbach's alpha reading of 0.96. As a result, the questionnaire material can be considered as fitting the relevant study sample and providing informative results.

\section{Research Procedures}

With the quantitative questionnaire having been established, a qualitative focus group was put in place. This stage of the process was overseen by a facilitator whose role was to relate the research's purposes and stress how vital the participants' responses were for enhancing SIS. The task then included gaining informed consent, with participants promised that any contributions taken from their responses would be used for nothing else than the defined scientific research. The students were then asked to make introductions, which revealed that some were familiar with each other, which served to enhance the group atmosphere. The subsequent discussion then focused on the questionnaire material they would be asked to respond to. Different volunteers then contributed to reading out a group of statements while the facilitator took notes and identified any queries or issues from the interactions. The participants also contributed with feedback in writing, and the focus group was concluded after around 50 minutes.

The responses and notes that were then gathered were assessed as per the "three coding-framework" of [50]. This enabled the researchers to comprehend many of the current issues and dynamics regarding how systems users are currently approaching their tasks while allowing the questionnaire material to be upgraded to suit. In general, the responses showed that participants found the questions clear and straightforward. Opportunities were still found, however, to remove or to blend some of the statements, meaning that the material was enhanced as a result. With the focus group process complete, the questionnaire could then be administered online with approval from PAAET's higher administration. With this approval obtained, all faculties then received the 
questionnaire with directions for rolling out to their students. A seven-day response period followed before the feedback was examined via SPSS, including frequency, percentage, mean, standard deviation (SD), and t-test.

\section{RESULTS AND DISCUSSION}

The questionnaire results are detailed here, focusing on those responses that capture the SIS perspectives. Furthermore, the research hypothesis is discussed concerning gender variations.

\section{A. Students' SIS Perceptions}

The findings from our assessment of participants' SIS perceptions are presented in this section. To provide a basis for analyzing the responses, the two categories of pragmatic and hedonic are applied. The sub-sections below contain tables to show percentages, means, standard deviations (SD), t-test, and how each item ranks in dimension due to the average mean values. Taken together, the data highlights variations between the genders in respect of their responses.

1) Pragmatic quality: Table II contains statistics relating to SIS's pragmatic features (task-oriented features), together with the capabilities relating to achieving 'do-goals' and its applicability regarding a range of possible tasks [11]. Analyzing the mean values identified within the Table II data (items 1 to 8 ) shows that participants tended to record a neutral-to-positive perspective of SIS and its worth, which did not seem to be affected by gender. In contrast, a neutral-todisagree perspective was recorded for Question 1 'All system commands are executed quickly,' with 2.79 being the average mean. The highest rank was achieved by system security, with participants showing 4.01 as an average mean value (as per item 8). Ease of use (item 5) came second, recording an average mean of 3.6; and system accuracy came third, recording an average mean of 3.44 (as per Question 6). Also, feedback for whether participants felt they had adequate SIS training (Question 4) produced a neutral-to-agree response and an average mean of 3.18 .

Taking the overall average mean of 3.36 from the pragmatic results, the research found that participants were slightly satisfied with the functions offered by SIS, together with its efficacy and usability. Based on this, Hypothesis 1 was analyzed, but Table II data highlights no substantial variations between the genders with one exception. For 'The SIS is an easy-to-use program' (item 5), the findings show significant gender variations for 'level of significance ( $p-0.03)$ in favor of female (t-test) $\mathrm{p}<0.05$.

2) Hedonic quality: Table III contains the findings relating to the hedonic aspects of SIS (the non-task-related UX features), which shows the system's recognized capabilities in terms of aiding its users' objective- in this example, the system's aesthetics [11]. Assessing the mean values indicated within the table shows that participants have a neutral-topositive perspective of SIS attractiveness, together with innovation, with no clear variation between the genders. The perspectives recorded on how data is graphically represented by SIS (Question 13), achieved the highest average mean value (4.16), with excitement coming second (Question 9, with an average mean of 3.29). The third place was taken by asking how interesting the system is (Question 10, with an average mean of 3.20). In contrast, the question regarding creativity only came seventh (Question 16, with an average mean of 3.13). In the last place was the question on attractiveness (Question 11, with an average mean of 2.95).

TABLE II. SIS EVALUATION "PRAGMatic Quality"

\begin{tabular}{|c|c|c|c|c|c|c|c|c|c|c|c|}
\hline & Question & Gender & $\begin{array}{l}\text { Strongly } \\
\text { Disagree }\end{array}$ & Disagree & Neutral & Agree & $\begin{array}{l}\text { Strongly } \\
\text { Agree }\end{array}$ & Mean & SD & Sig. & Rank \\
\hline \multirow{2}{*}{ Q1 } & \multirow{2}{*}{$\begin{array}{l}\text { All system commands are } \\
\text { executed quickly. }\end{array}$} & male & 10 & 16 & 33 & 42 & 19 & 2.86 & 1.380 & \multirow{2}{*}{0.52} & \multirow{2}{*}{8} \\
\hline & & female & 58 & 67 & 143 & 190 & 67 & 2.77 & 1.428 & & \\
\hline \multirow{2}{*}{ Q2 } & \multirow{2}{*}{$\begin{array}{l}\text { I believe that the SIS meets my } \\
\text { requirements. }\end{array}$} & male & 16 & 18 & 22 & 43 & 21 & 3.29 & 1.292 & \multirow{2}{*}{0.82} & \multirow{2}{*}{5} \\
\hline & & female & 71 & 78 & 96 & 202 & 78 & 3.26 & 1.266 & & \\
\hline \multirow{2}{*}{ Q3 } & \multirow{2}{*}{$\begin{array}{l}\text { I think the SIS is practical and } \\
\text { effective. }\end{array}$} & male & 17 & 18 & 24 & 37 & 24 & 3.28 & 1.328 & \multirow{2}{*}{0.87} & \multirow{2}{*}{6} \\
\hline & & female & 73 & 76 & 102 & 193 & 81 & 3.25 & 1.275 & & \\
\hline \multirow{2}{*}{ Q4 } & \multirow{2}{*}{$\begin{array}{l}\text { I got enough training on how to } \\
\text { use the SIS. }\end{array}$} & male & 19 & 21 & 17 & 44 & 19 & 3.19 & 1.337 & \multirow{2}{*}{0.95} & \multirow{2}{*}{7} \\
\hline & & female & 68 & 101 & 92 & 195 & 69 & 3.18 & 1.256 & & \\
\hline \multirow{2}{*}{ Q5 } & \multirow{2}{*}{$\begin{array}{l}\text { The SIS is an easy-to-use } \\
\text { program. }\end{array}$} & male & 14 & 17 & 25 & 35 & 29 & 3.40 & 1.312 & \multirow{2}{*}{0.03} & \multirow{2}{*}{2} \\
\hline & & female & 29 & 66 & 94 & 202 & 134 & 3.66 & 1.149 & & \\
\hline \multirow{2}{*}{ Q6 } & \multirow{2}{*}{$\begin{array}{l}\text { The SIS performs my } \\
\text { registration accurately. }\end{array}$} & male & 12 & 17 & 23 & 44 & 24 & 3.43 & 1.241 & \multirow{2}{*}{0.81} & \multirow{2}{*}{3} \\
\hline & & female & 38 & 75 & 111 & 213 & 88 & 3.45 & 1.143 & & \\
\hline \multirow{2}{*}{ Q7 } & \multirow{2}{*}{ The SIS is reliable. } & male & 14 & 20 & 21 & 37 & 28 & 3.38 & 1.322 & \multirow{2}{*}{0.86} & \multirow{2}{*}{4} \\
\hline & & female & 57 & 69 & 108 & 190 & 101 & 3.40 & 1.242 & & \\
\hline \multirow{2}{*}{ Q8 } & \multirow{2}{*}{ The SIS is secured. } & male & 5 & 8 & 16 & 46 & 45 & 3.98 & 1.077 & \multirow{2}{*}{0.68} & \multirow{2}{*}{1} \\
\hline & & female & 25 & 8 & 74 & 240 & 178 & 4.02 & 0.985 & & \\
\hline
\end{tabular}


TABLE III. SIS EVALUATION "HEDONIC QUALITY"

\begin{tabular}{|c|c|c|c|c|c|c|c|c|c|c|c|}
\hline & Question & Gender & $\begin{array}{l}\text { Strongly } \\
\text { Disagree }\end{array}$ & Disagree & Neutral & Agree & $\begin{array}{l}\text { Strongly } \\
\text { Agree }\end{array}$ & Mean & SD & Sig. & Rank \\
\hline \multirow{2}{*}{ Q9 } & \multirow{2}{*}{$\begin{array}{l}\text { The screen of SIS is } \\
\text { exciting. }\end{array}$} & male & 10 & 16 & 33 & 42 & 19 & 3.37 & 1.152 & \multirow{2}{*}{0.41} & \multirow{2}{*}{2} \\
\hline & & female & 58 & 67 & 143 & 190 & 67 & 3.27 & 1.171 & & \\
\hline \multirow{2}{*}{ Q10 } & \multirow{2}{*}{$\begin{array}{l}\text { The SIS is an interesting } \\
\text { system. }\end{array}$} & male & 13 & 15 & 28 & 42 & 22 & 3.38 & 1.230 & \multirow{2}{*}{0.10} & \multirow{2}{*}{3} \\
\hline & & female & 82 & 80 & 106 & 186 & 71 & 3.16 & 1.284 & & \\
\hline \multirow{2}{*}{ Q11 } & \multirow{2}{*}{$\begin{array}{l}\text { The SIS interface is } \\
\text { attractive. }\end{array}$} & male & 14 & 34 & 34 & 26 & 12 & 2.90 & 1.170 & \multirow{2}{*}{0.65} & \multirow{2}{*}{8} \\
\hline & & female & 82 & 108 & 146 & 129 & 60 & 2.96 & 1.239 & & \\
\hline \multirow{2}{*}{ Q12 } & \multirow{2}{*}{ The SIS is stimulating. } & male & 14 & 22 & 33 & 31 & 20 & 3.18 & 1.248 & \multirow{2}{*}{0.49} & \multirow{2}{*}{5} \\
\hline & & female & 53 & 86 & 130 & 184 & 72 & 3.26 & 1.184 & & \\
\hline \multirow{2}{*}{ Q13 } & \multirow{2}{*}{$\begin{array}{l}\text { Graphics showing students' } \\
\text { performance is challenging. }\end{array}$} & male & 6 & 5 & 12 & 43 & 54 & 4.12 & 1.078 & \multirow{2}{*}{0.62} & \multirow{2}{*}{1} \\
\hline & & female & 11 & 26 & 58 & 200 & 230 & 4.17 & 0.954 & & \\
\hline \multirow{2}{*}{ Q14 } & \multirow{2}{*}{$\begin{array}{l}\text { The SIS is an interesting } \\
\text { system }\end{array}$} & male & 17 & 20 & 30 & 34 & 19 & 3.15 & 1.281 & \multirow{2}{*}{0.47} & \multirow{2}{*}{6} \\
\hline & & female & 66 & 85 & 117 & 170 & 87 & 3.24 & 1.263 & & \\
\hline \multirow{2}{*}{ Q15 } & \multirow{2}{*}{$\begin{array}{l}\text { The SIS is an innovative } \\
\text { system. }\end{array}$} & male & 16 & 21 & 34 & 28 & 21 & 3.14 & 1.279 & \multirow{2}{*}{0.13} & \multirow{2}{*}{4} \\
\hline & & female & 41 & 100 & 124 & 165 & 95 & 3.33 & 1.198 & & \\
\hline \multirow{2}{*}{ Q16 } & \multirow{2}{*}{$\begin{array}{l}\text { The SIS is a creative } \\
\text { system. }\end{array}$} & male & 18 & 24 & 24 & 32 & 22 & 3.13 & 1.341 & \multirow{2}{*}{0.95} & \multirow{2}{*}{7} \\
\hline & & female & 60 & 109 & 129 & 159 & 68 & 3.13 & 1.214 & & \\
\hline
\end{tabular}

Calculating the overall average mean for SIS's hedonistic qualities gives us 3.31, recording a neutral-to-slightly satisfying response regarding innovation, attractiveness, and stimulation. Taking a t-test to look more closely at gender dynamics (based on Table III data) highlights no substantial variation between genders regarding 'level of significance.' Plus, a t-test result of $\mathrm{p}<0.05$ establishes that the results do not confirm Hypothesis 2.

\section{B. Pragmatic vs. Hedonic Qualities of the SIS}

The two categories of pragmatic and hedonic are utilized for analyzing the interactive qualities of SIS. In this context, the pragmatic tends to be linked to task-oriented features. In contrast, hedonic indicates features unrelated to the task's users carry out, but which nevertheless prove crucial to the attractiveness and interactivity offered in pursuit of such objectives [11]. The findings detailed in the sections above highlight respondents' perspectives regarding SIS in respect of both pragmatic and hedonic contexts. Their feedback shows that SIS is considered essential in respect of enabling learners to register courses and access their records to suit deadlines and the completion of quality work. Comparing the scores shows that feedback on pragmatic aspects results in a slightly higher average mean of 3.36 against 3.31 - as per Fig. 1 .

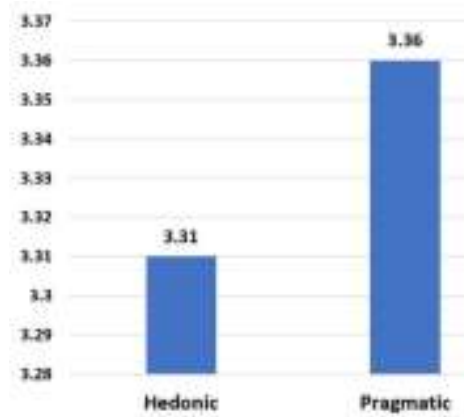

Fig. 1. Pragmatic vs. Hedonic Quality of the SIS.
The findings highlight the need for SIS enhancements to meet users' expectations in a manner that upgrades efficacy, usability, attractiveness, innovation, productivity, and learnability. Productivity relates to speed and convenience, enabling learners to complete their objectives swiftly. In contrast, efficacy concerns the precision they are allowed in meeting their goals without being held back by data entry issues or performance restrictions [51]. Numerous methods allow developers to attempt such SIS upgrades. To achieve ease-of-use within a system, those working on its features need to allow students the means of adapting to new features without encountering major learning curves along the way. The most effective route to securing such upgrades is to focus on SIS aspects that sync with the user's current capabilities. Indeed, developers should provide staged upgrades to functionality so that the technology never lacks familiarity. The researchers of $[52,53]$ all advise educational institutions to consider effective training and guidance where possible so that learners can always make the most of their systems' potentials. Therefore, the development and release of training advice via online videos and tutorials and more focused training programs for both genders should enable seamless SIS upgrades.

The results also offer guidance for prioritizing SIS aesthetics by introducing dynamic and attractive new functionalities. Including creativity within developers' enhancements can prove to define when it comes to engaging with students, handling issues in a way that is both innovative and enticing. The research of [54] also highlights creativity as integral to upgrading the efficacy and usability of SIS, highlighting numerous positives resulting from presenting software and innovations in a versatile and artistic manner. The authors in [55] and [56] both focus on attractiveness as essential despite being a hedonistic quality, identifying numerous benefits in how students comprehend and utilize the tools and materials available. Furthermore, the efforts taken to achieve quality graphics help to stimulate users due to appealing visuals. Any additions that allow for speedier 
comprehension of instructions or data help users take charge of the tools at hand [57]. According to Human-Computer Interaction research, the benefits of quality aesthetics on learners' subjective impressions and their subsequent responses are widely acknowledged. Extensive research points to the potential of aesthetic interfaces heightening engagement levels that users can achieve [58, 59, 60]. As per [59], a practical approach to aesthetics is advised because users respond to such dynamics.

\section{Differences According to Gender}

This examination records Hypothesis 1 as being reached in part, finding no substantial variation between the genders, apart from concerning participants' usability - as explored in the section regarding pragmatic qualities that resulted in substantial variations with a 'level of significance' $(\mathrm{p}=0.03)$, in favor of female (t-test) $\mathrm{p}<0.05$. For Hypothesis 2 , however, no substantial variations were identified regarding how either gender views SIS's hedonistic qualities.

The variations that do exist between genders can affect how they approach and utilize online technology. Learners' perspectives differ according to various user features, for example, individual characteristics, cognitive tendencies, age and gender, and previous experience that can shape opinions of and behaviors toward SIS [15]. Furthermore, the utilization of online tools may vary between the genders because of societal dynamics. For example, in Kuwait, it is predicted that both men and women will utilize online media for social purposes before any other use as a result of belonging to a collectivist culture, which is also affected by the country's education system being gender-segregated. Despite this research identifying SIS evaluation results that can be drawn upon to help designers upgrade systems, the findings also point to the genders showing no favoritism in terms of either aesthetics or functionality.

\section{CONCLUSION}

According to SIS perspectives, this research has examined gender variations - an essential component to any modern educational facility - via learners' opinions and responses to its various dynamics. The UX positives and negatives recorded according to SIS's use within PAAET institutions have been analyzed under the context of pragmatic or hedonic use, which stand for the two vital elements of an effective system. By combining qualitative and quantitative approaches, the responses gathered from 645 PAAET participants informed the results. Also, for qualitative purposes, a focus group meeting took place to gain some prior insight into participants' utilization and opinions of the applicable SIS to refine the materials that would make up the questionnaire. When combined, the focus group findings and the survey data statistical analysis suggest that the students' opinions toward SIS were slightly positive.

Regarding UX dynamics, the pragmatic qualities are considered slightly more favorable than hedonic ones -3.36 versus 3.31. The findings call for SIS upgrades to meet users' objectives, with a particular focus on creativity and attractiveness among the innovative steps taken. Consequently, throughout the PAAET facilities, the SIS is no longer completely applicable to the learning objectives and delivery methods that will bring the best out of learners. More effective and engaging systems need to be developed so that students can realize their academic potential, specifically via attractive visual dashboards and many other features enhanced by better quality graphics. As a result, the constant review and upgrading of SIS features via wide-scale research and analyses are crucial if systems remain robust. Continuous feature improvements regularly further the productive nature of students' SIS use via interactivity.

This research's findings are applicable to usability developers' concerns, together with any professionals with a vested interest in how SIS use varies between the genders. Two key hypotheses have been trialed in a gender context to represent both pragmatic and hedonic SIS features. Notable variations were identified between the genders as far as pragmatic features are concerned, but not with hedonic features. The results heighten awareness of SIS potential within PAAET, particularly regarding developers' requirements to carry out UX assessments. The example included which was shown to be applicable and effective in informing upgrades based on context. Upgrading and innovating systems based on creativity and attractiveness will make SIS more accessible and engaging to both genders, having a knock-on effect on educational performance via value and productivity.

\section{ACKNOWLEDGMENT}

This research was supported and funded by the Public Authority for Applied Education and Training, project number: BS-19-03.

\section{REFERENCES}

[1] A. Al-Hunaiyyan, A. Bimba and S. Al-Sharhan, "A cognitive knowledge-based model for an adaptive e-advising system.," Interdisciplinary Journal of Information, Knowledge, and Management (IJIKM), Volume 15, pp. 247-263, 2020.

[2] A. Al-Hunaiyyan, S. Al-Sharhan and R. Al-Hajri, "Prospects and Challenges of Learning Management Systems in Higher Education," International Journal of Advanced Computer Science and Applications (IJACSA), Vol. 11, No. 12, pp. 73-79, 2020.

[3] S. Mukerjee, "Student information systems - implementation challenges and the road ahead," Journal of Higher Education Policy and Management, 34(1), 51-60. https://doi.org/10.1080/1360080X.2012. 642332, p. 51-60, 2012.

[4] S. Rochimah, H. Rahmani and U. Yuhana, "Usability characteristic evaluation on administration module of Academic Information System using ISO/IEC 9126 quality model 2015," in International Seminar on Intelligent Technology and Its Applications (ISITIA). doi: 10.1109/ISITIA.2015.7220007, Surabaya, 2015.

[5] C. Guarin, E. Guzman and F. Gonzalez, "A Model to Predict Low Academic Performance at a Specific Enrollment Using Data Mining," IEEE Revista Iberoamericana De Tecnologias Del Aprendizaje, 10 (3), pp. 119-125, 2015.

[6] H. Widodo , M. Kertahadi and I. Suyadi, "The Influence of Job Relevant Information, Task Technology Fit, and Ease of Use Information Technology Due to the User Performance: A Case Study on the and Use of Academic and Financial Information System in University of Brawijaya," Asian Journal of Social Sciences \& Humanities, 4 (2), pp. 128-138, 2015.

[7] J. Nielsen, Designing User Interfaces for International Use, New Yorylk: Elsevier, 1990.

[8] R. Alhajri, S. Al-Sharhan, A. Al-Hunaiyyan and T. Alothman, "Design of educational multimedia interfaces: individual differences of learners," 
in Proceedings of the Second Kuwait Conference on e-Services and eSystems, Kuwait, 2011.

[9] N. Al-Huwail, S. Al-Sharhan and A. Al-Hunaiyyan, "Learning Design for a Successful Blended E-learning Environment: Cultural Dimensions," INFOCOMP. Journal of Computer Science, Volume 6 No. 4, pp. 60-69, 2007.

[10] A. Al-hunaiyyan, S. Al-Sharhan and R. Alhajri, "Instructors Age and Gender Differences in the Acceptance of Mobile Learning," International Journal of Interactive Mobile Technologies (iJIM). Vol. 11, No. 4, 2017

[11] M. Hassenzahl, "User experience (UX): Towards an experiential perspective on product quality," in Proceedings of the 20th International Conference of the Association Francophone d'Interaction HommeMachine on - IHM '08 DOI:10.1145/1512714.1512717., New York, 2008.

[12] A. Hinderks, M. Schrepp and J. Thomaschewski, "A Benchmark for the Short Version of the User Experience Questionnaire," in Proceedings of the 14th Inernational Conference on Web Information (WEBIST), 2018.

[13] M. Rauschenberger, M. Schrepp, M. Cota, S. Olschner and J. Thomaschewski, "Efficient Measurement of the User Experience of Interactive Products. How to use the User Experience Questionnaire (UEQ). Example: Spanish Language Version," International Journal of Interactive Multimedia and Artificial Intelligence. Vol. 2, $\mathrm{N}^{\circ} 1$. DOI: 10.9781/ijimai.2013.215, pp. 39-45, 2013.

[14] M. Schrepp, A. Hinderks and J. Thomaschewski, "Design and Evaluation of a Short Version of the User Experience Questionnaire (UEQ-S)," International Journal of Interactive Multimedia and Artificial Intelligence. 4.103, 2017.

[15] R. Alhajri, A. Alhunaiyyan and E. AlMousa, "Understanding the Impact of Individual Differences on Learner Performance Using Hypermedia Systems," International Journal of Web-Based Learning and Teaching Technologies (IJWLTT), 12(1). doi:10.4018/IJWLTT.2017010101, pp. $1-18,2017$.

[16] A. Al-Kandari, A. Al-Hunaiyyan and R. Alhajri, "The Influence of Culture on Instagram Use," Journal of Advances in Information Technology, vol. 7, no. 1, pp. 54-57, 2016.

[17] A. Al-Kandari, F. Al-Sumait and A. Al-Hunaiyyan, "Ali A. Al-Kandari, Fahad Y. Al-Sumait \& Ahmed Al-Hunaiyyan (2017) Looking perfect: Instagram use in a Kuwaiti cultural context," Journal of International and Intercultural Communication, Volume 10, Issue 4, https://doi.org/10.1080/17513057.2017.1281430, pp. 273-290, 2017.

[18] F. Dashti and A. Aldashti, "EFL College Students' Attitudes towards Mobile Learning," International Education Studies, vol. 8, no. 8, pp. 1320, 2015.

[19] S. Al-Sharhan, A. Al-Hunaiyyan and H. Al-Sharrah, "A new efficient blended e-learning model and framework for k12 and higher education: Design and," in 2010 fifth international conference, 2010.

[20] A. Al-Hunaiyyan, S. Al-Sharhan and R. Alhajri, "Instructors Age and Gender Differences in the Acceptance of Mobile Learning," International Journal of Interactive Mobile Technologies (iJIM). Vol. 11, No. 4, 2017.

[21] P. Morville, "User Experience Design," 2014. [Online]. Available: http://semanticstudios.com/user_experience_design/.

[22] D. Demirkol and C. Seneler, "Evaluation of a Student Information System (SIS) in terms of User Emotions, Performance and Perceived Usability: A Pilot Study," in XV. European Conference on Social and Behavioral Sciences, Kusadasi, Turkey, 2018.

[23] M. Gemmell and R. Pagano:, "A Post-Implementation Evaluation of a Student Information System in the UK Higher Education Sector," The Electronical Journal of Information Systems Evaluation, 6(2), 2003.

[24] M. R. Nordaliela, H. Suriani and E. L. Nathaniel, "Usability Analysis of Students Information System in a Public University.," Journal of Emerging Trends in Engineering and Applied Sciences (JETEAS) 4(6), pp. 806-810, 2013.

[25] I. Sherifi, "Impact of information systems in satisfying students of the university: Case study from Epoka University," European Journal of Business and Social Sciences, pp. 167-175, 2015.

[26] A. Alzahrani, I. Mahmmud,, T. Ramayah, O. Alfarraj and N. Alalwan, "Alzahrani, A., Mahmmud, I., Ramayah, T., Alfarraj, O., \& Alalwan, N.
(2017). Modelling digital library success using the DeLone and McLean information system success model.," Journal of Librarianship and Information Science 51(2), 2017.

[27] C. Gurkut and M. Cemal Nat, "Important Factors Affecting Student Information System Quality and Satisfaction," Eurasia Journal of Mathematics, Science and Technology Education.14(3), pp. 923-932, 2017.

[28] S. Tabrizi, C. Tufekci, O. Gumus and A. Cavus, "Usability Evaluation for Near East University Student Information System. , pp 235-243," New Trends and Issues Proceedings on Humanities and Social Sciences. 03, pp. 235-243, 2017.

[29] D. Demirkola and C. Seneler, "Evaluation of Student Information System (SIS) In Terms of User Emotion, Performance and Perceived Usability: A Turkish University Case (An Empirical Study)," Procedia Computer Science 158, pp. 1033-1052, 2019.

[30] K. Mir and A. Mehmood, ". (2016). Examining the Success Factors of Online Student Support System at AIOU.," in Pan-Commonwealth Forum 8 (PCF8), KLCC, KL. Malaysia, 2016.

[31] A. Eludire, "The Design and Implementation of Student Academic Record Management System," Research Journal of Applied Sciences, Engineering and Technology, Osun State, Nigeria, vol. 3, no. 8, pp. 707712, 2011.

[32] A. Farid, "Improve the usability of student information system at Aden Universit," International Journal of Contemporary Computer Research (IJCCR), Vol.1 Issue.1, 2016.

[33] H. Hijazi-Omari and R. Ribak, "PLAYING WITH FIRE: On the domestication of the mobile phone among Palestinian teenage girls in Israel," Information, Communication \& Society Vol. 11 , Issue 2, 2008.

[34] N. Baron and Y. Hård af Segerstad, "Cross-cultural patterns in mobile phone use: Public space and reachability in Sweden, the USA, and Japan," New Media \& Society 12(1), pp. 13-34, 2010.

[35] T. Goh, "Exploring Gender Differences in SMS-Based Mobile Library Search System Adoption," Educational Technology \& Society, 14 (4), p. 192-206, 2011.

[36] N. Baron and E. Campbell, " Gender and mobile phones in crossnational context," Language Sciences 34 (2012), p. 13-27, 2012.

[37] E. W. Baker, S. S. Al-Gahtani and G. S. Hubona, "The effects of gender and age on new technology implementation in a developing country: Testing the theory of planned behavior (TPB)," Information Technology \& People, vol. 20, no. 4, p. 352-375, 2007.

[38] G. Boy, The Hand book o fHuman-Machine Interaction: A HumanCentered Design Approach, 1st ed. edition, Milton: CRC Press, 2017.

[39] Prayaq, "The Importance of User Experience Design," 2019. [Online]. Available: https://uxplanet.org/the-importance-of-user-experiencedesign-988faf6ddca2?gi=59cd019477c9.

[40] A. Al-Hunaiyyan, Design of Multimedia Software in Relation to Users' Culture. Ph.D thesis, University of Hertfordshire, UK, 2000.

[41] J. Lewis and J. Sauro, "what's the difference between pragmatic and hedonic usability?," 17 May 2020. [Online]. Available: https://measuringu.com/pragmatic-hedonic/.

[42] P. Zimmermann, Beyond Usability - Measuring Aspects of User Experience. Thesis for: $\mathrm{PhD}$, Zurich: Swiss Federal Institute of Technology Zurich, 2008.

[43] M. Hassenzahl, A. Platz, M. Burmester and K. Lehner, "Hassenzahl, Marc \& Platz, Axel \& Burmester, Michael \& Lehner, Katrin. (2000). Hedonic and ergonomic quality aspect determine a software's appeal," in Proceedings of the CHI 2000 Conference on Human Factors in Computing Systems. The Netherlands, April 1-6, 2000. 10.1145/332040.332432., 2000.

[44] M. Hassenzahl, "The Effect of Perceived Hedonic Quality on Product Appealingness," International Journal of Human-Computer Interaction, 13:4, DOI: 10.1207/S15327590IJHC1304_07, pp. 481-499, 2001.

[45] S. Kujala, V. Roto, K. Väänänen-Vainio-Mattila and A. Sinnelä, "2001. Identifying Hedonic Factors in Long-Term User Experience," in Proceedings of the 2011 Conference on Designing Pleasurable Products and Interfaces. June 22-25, 2011. https://doi.org/10.1145/2347504.2347523, Milan, Italy, 2011. 
[46] T. Merčun and M. Žumer, "Exploring the influences on pragmatic and hedonic aspects of user experience," in Proceedings of the Ninth International Conference on Conceptions of Library and Information Science, June 27-29, 2016, Uppsala, Sweden, 2016.

[47] J. Preece, Y. Rogers and H. Sharp, Interaction Design: Beyond HumanComputer Interaction, 4th Edition, Indiannapolis: Wiley \& Sons, Inc, 2015.

[48] V. Basili, G. Caldiera and D. Rombach, "The Goal Question Metric Approach," Encyclopedia of software engineering, pp. 528-532, 1994.

[49] B. Laugwitz, T. Held and M. Schrepp, "Construction and Evaluation of a User Experience Questionnaire," in HCI and Usability for Education and Work. USAB 2008. Lecture Notes in Computer Science, vol 5298, Berlin, Heidelberg, Springer, 2008.

[50] T. Nyumba, K. Wilson, C. Derrick and N. Mukherjee, "The use of focus group discussion methodology: Insights from two decades of application in conservation," Methods in Ecology and Evolution (MEE), 9, p. 2032, 2018.

[51] W. Quesenbery, "What Does Usability Mean: Looking Beyond 'Ease of Use'," 12 December $2020 . \quad$ [Online]. Available: https://www.wqusability.com/articles/more-than-ease-of-use.html.

[52] S. Al-Sharhan, A. Al-Hunaiyyan, R. Alhajiri and N. Al-Huwail, "Utilization of Learning Management System (LMS) Among Instructors and Students," in Advances in Electronics Engineering. Lecture Notes in Electrical Engineering, vol 619, Singapore, Springer, 2020, pp. 15-23.

[53] A. Johnson, M. Jacovina, D. Russell and C. Soto, "Challenges and solutions when using technologies in the classroom," in Adaptive educational technologies for literacy instruction, New York, Taylor \& Francis, 2016, pp. 13-29.
[54] R. McDaniel, R. Fanfarelli and R. Lindgren, "Creative Content Management: Importance, Novelty, and Affect as Design Heuristics for Learning Management Systems," IEEE Transactions on Professional Communication, vol. 60, no. 2, pp. 183-200, 2017.

[55] M. Baharum, Z. Zainul Rashid, Z. Husin, S. Sahat and Z. Abu, "An evaluation of Universiti Teknologi Mara branch campuses websites towards acceptance among staff," in in 2011 IEEE Conference on Open Systems, 2011.

[56] Y. He, C. Cheng, Q. Xu and L. Yang, "A research on methods and applications of case study in public administration," in International Conference on Management Science Engineering 21th Annual Conference Proceedings, Helsinki, Finland, 2014.

[57] MindTools.com, "Charts and Graphs: choosing the Right Visual For Your Data," 2020. [Online]. Available: https://www.mindtools.com/ pages/article/Charts_and_Diagrams.htm. [Accessed 153 2020].

[58] C. Miller, "Aesthetics and E-Assessment: the interplay of emotional design and learner performance," Distance Education ;32, p. 307-337, 2011.

[59] M. Thielsch, R. Haines and L. Flacke, "Experimental investigation on the effects of website aesthetics on user performance in different virtual tasks," PeerJ, 7, e6516, 2019.

[60] P. Van Schaik and J. Ling, "Modelling user experience with web sites: usability, hedonic value, beauty and goodness," Interacting with Computers, 2008;20, p. 419-432, 2008. 